Annals of International Medical and Dental Research

E-ISSN: 2395-2822 | P-ISSN: 2395-2814

Vol-8, Issue-1 | January-February 2022

DOI: $10.53339 /$ aimdr.2022.8.1.23

Page no- 175-179 | Section- Research Article (Anatomy)

\title{
A Cadaveric Study of Palmaris Longus Muscle
}

\section{Santosh Vaman Waghmode1, Sadiqali Abbasali Syed²*}

\begin{abstract}
${ }^{1}$ Assistant Professor, Department of Anatomy, Government Medical College, Miraj, Maharashtra, India. Email: officialsurya24by7@gmail.com Orcid ID: 0000-0002-4112-2122

${ }^{2}$ Assistant Professor, Department of Anatomy, Government Medical College, Miraj, Maharashtra, India. Email: sadiqalisyed23@gmail.com Orcid ID: 0000-0002-4281-6839

*Corresponding author
\end{abstract}

Received: 02 October 2021

Revised: 03 November 2021

Accepted: 12 November 2021

Published: 22 December 2021

\begin{abstract}
Background: Aim: To assess the palmaris longus muscle. Methods: 40 formalin fixed cadavers of both genders were included. Routine dissection of the upper limb was carried following the Cunnigham's Manual of Practical Anatomy. During the dissection of the anterior compartment of forearm, the Palmaris longus muscle was identified \& carefully dissected. Results: Out of 40 cadavers, 22 were of males and 18 were of females. Morphology of Palmaris longus found to be normal in 18, agenesis in 6, fusiform in 4, hybrid in 6, bifurcated tendon in 5 and fleshy in 1 case. A significant difference was observed $(\mathrm{P}<0.05)$. Conclusions: Surgeon must be aware of the variations of palmaris longus muscle. Morphology of Palmaris longus found to be normal, agenesis, fusiform, hybrid, bifurcated tendon and fleshy.
\end{abstract}

Keywords:- Palmaris longus, fusiform, hybrid, Fleshy.

\section{INTRODUCTION}

Palmaris longus is described as a slender superficial flexor muscle of the forearm. ${ }^{[1]}$ The muscle belly is fusiform in shape which takes origin from the anterior surface of medical epicondyle of humerus in common with the other superficial flexor muscles of forearm, just medial to flexor carpi radialis muscle.[2] It converges to form a long tendon, which passes superficial to flexor retinaculum and then the tendon broadens out to form a flat sheet which gets attached to the apex of palmar aponeurosis.[3,4] Palmaris longus muscle is innervated by median nerve $(C 7, C 8)$ and "phylogenetically it is a degenerate metacarpophalangeal joint flexor" and a weak flexor of the wrist joint. At the wrist, median nerve lies partly undercover of palmaris longus or between the tendons of flexor carpi radialis and palmaris longus.[]

In evolutionary history it is seen to be prominent in mammals that use their forelimbs for ambulation and a well- developed muscle is seen in the orangutan but is vestigial in humans. In predatory animals, it assists in claw retraction.6] Numerous variations have been reported in both morphology and number.[7] It may have a proximal tendon or a distal tendon, or have a fleshy central belly with proximal and distal tendons, it maybe digastric or fleshy throughout or its tendon may be split and sometimes it maybe degenerated to such an extent it that may be simply represented by a tendinous band. When it is tendinous proximally and has a fleshly distal belly it is called reverse Palmaris Longus or Palmaris 
Annals of International Medical and Dental Research

E-ISSN: 2395-2822 | P-ISSN: 2395-2814

Vol-8, Issue-1 | January-February 2022

DOI: 10.53339/aimdr.2022.8.1.23

Page no- 175-179 | Section- Research Article (Anatomy)

Longus inversus.[] During routine dissection for MBBS students in Government Medical College, Miraj, we encountered an agenesis of Palmaris Longus. Variations of palmaris longus are common but asymptomatic; they may become important during surgeries and in some radiological procedures. Awareness of such variations is important. [9] Considering this, the present study aimed at assessing Palmaris Longus muscle.

\section{MATERIAL AND METHODS}

The present study comprised of 40 formalin fixed cadavers of both genders. The study protocol was approved from ethical review and clearance committee.

Routine dissection of the upper limb was carried following the Cunnigham's Manual of Practical Anatomy. During the dissection of the anterior compartment of forearm, the Palmaris longus muscle was identified \& carefully dissected. At first, the origin was confirmed and then, it was traced towards its insertion. Any variation, its nerve supply and its relation to flexor retinaculum and neighbouring structures found were recorded. After recording all the parameters, statistical analysis was carried out using Mann Whitney U test. Level of significance was set below 0.05.

\section{RESULTS}

Out of 40 cadavers, 22 were of males and 18 were of females [Table 1].

Morphology of Palmaris longus found to be normal in 18, agenesis in 6, fusiform in 4, hybrid in 6, bifurcated tendon in 5 and fleshy in 1 case. A significant difference was observed $(\mathrm{P}<0.05)$ [Table 2, Figure 1].

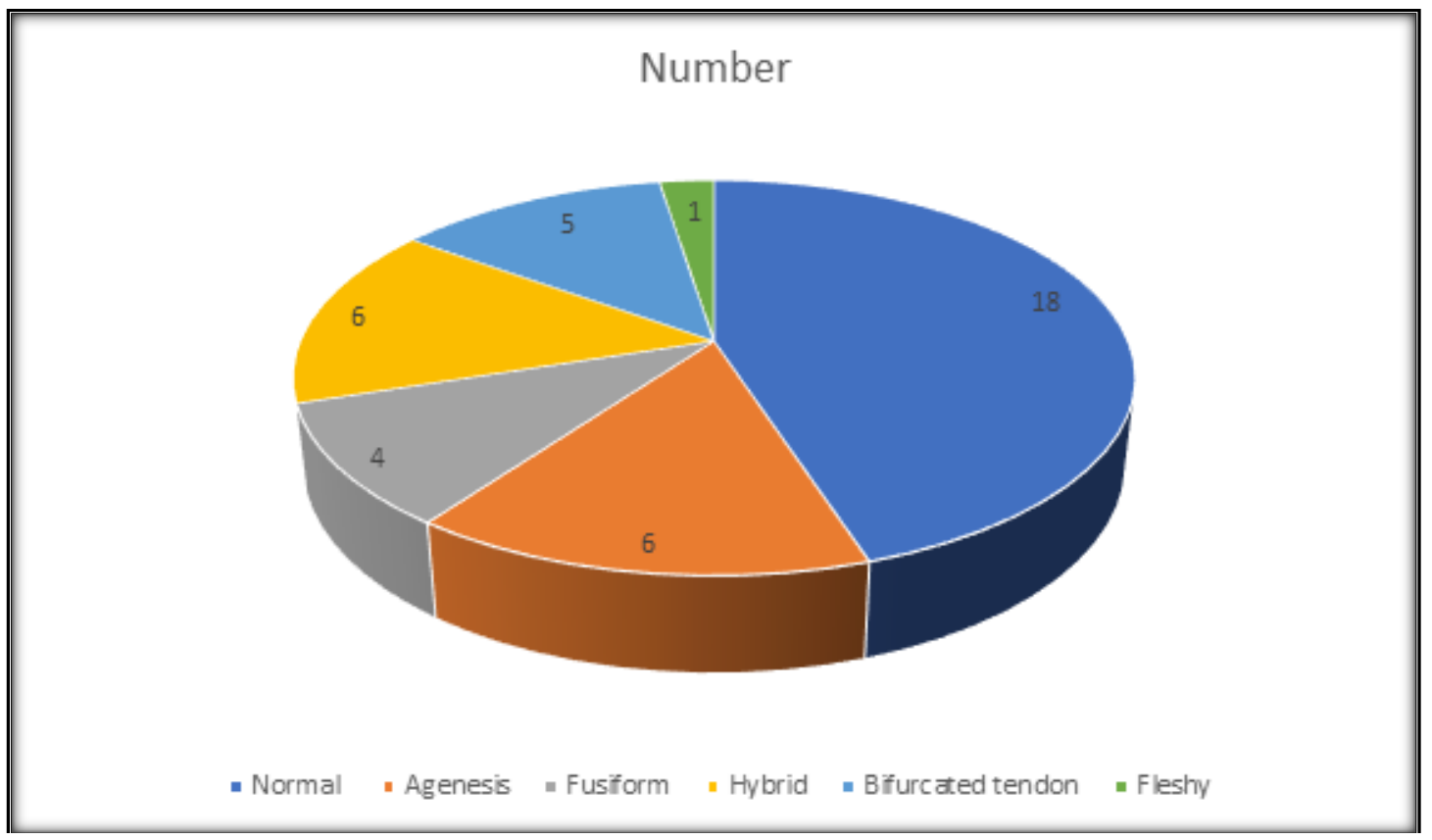

Figure 1: Type of morphology 
Annals of International Medical and Dental Research

E-ISSN: 2395-2822 | P-ISSN: 2395-2814

Vol-8, Issue-1 | January-February 2022

DOI: $10.53339 /$ aimdr.2022.8.1.23

Page no- 175-179 | Section- Research Article (Anatomy)

Table 1: Distribution of patients.

\begin{tabular}{|l|l|l|}
\hline \multicolumn{2}{|c|}{ Total- 40 } \\
\hline Gender & Males & Females \\
\hline Number & 22 & 18 \\
\hline
\end{tabular}

Table 2: Type of morphology.

\begin{tabular}{|l|l|l|}
\hline Morphology & Number & P value \\
\hline Normal & 18 & \multirow{2}{*}{0.01} \\
\hline Agenesis & 6 & \\
\hline Fusiform & 4 & \\
\hline Hybrid & 6 & \\
\cline { 1 - 2 } Bifurcated tendon & 5 & \\
\hline Fleshy & 1 & \\
\hline
\end{tabular}

\section{DISCUSSION}

Palmaris longus muscle is innervated by median nerve (C7, C8) and "phylogenetically it is a degenerate metacarpophalangeal joint flexor" and a weak flexor of the wrist joint.[10] At the wrist, median nerve lies partly undercover of palmaris longus or between the tendons of flexor carpi radialis and palmaris longus. Palmaris longus is often absent on one or both sides.[11] The literature reports that the Palmaris longus muscle is a sex-linked dominant trait more absent in females. Studies reported that the absence of the Palmaris longus is not correlated with a decrease in the strength of one's grip or pinch.[12,13] Numerous variations have been reported in both morphology and number.[14] It may have a proximal tendon or a distal tendon, or have a fleshy central belly with proximal and distal tendons, it maybe digastric or fleshy through out or its tendon may be split and sometimes it maybe degenerated to such an extent it that may be simply represented by a tendinous band. When it is tendinous proximally and has a fleshly distal belly it is called reverse PL or
PL inversus.15] The present study aimed at assessing palmaris muscle.

Our study demonstrated that out of 40 cadavers, 22 were of males and 18 were of females. Mathew et al,[16] estimated the presence, variants and nerve supply of the PL. Upper extremity of 24 cadavers was dissected and PL was examined. The results were compared to other studies on the PL and literature survey was carried out. Thirty- nine specimens showed normal morphology and four showed complete agenesis. Other morphological variations seen included reversed, hybrid, fusiform, fleshy and bifurcated tendon of insertion. Every surgeon must be aware of the variations of the versatile but temperamental PL.

We observed that Morphology of Palmaris longus found to be normal in 18, agenesis in 6, fusiform in 4, hybrid in 6, bifurcated tendon in 5 and fleshy in 1 case. Sunitha et al,[17] studied the variations in the Palmaris longus and to discuss the embryological basis, clinical and surgical implications of these variations. Thirty 
Annals of International Medical and Dental Research

E-ISSN: 2395-2822 | P-ISSN: 2395-2814

Vol-8, Issue-1 | January-February 2022

DOI: 10.53339 /aimdr.2022.8.1.23

Page no- 175-179 | Section- Research Article (Anatomy)

formalin fixed cadavers (60 upper limbs); 25 males \& 5 female cadavers were dissected for the study. During the dissection of the anterior compartment of forearm, the Palmaris longus muscle was identified \& carefully dissected. At first, the origin was confirmed and then, it was traced towards its insertion. Any variations found were noted and photographed. The results were analysed and compared to previous studies. Bilateral absence of palmaris longus was seen in one male cadaver and unilateral (right sided) absence in one female cadaver. Percentage of bilateral absence of palmaris longus is $3.3 \%$. Total absence of palmaris longus is $5 \%$. Right side absence is $3.3 \%$, left side absence is $1.6 \%$. Variations like split tendon of palmaris longus was observed in a female cadaver on right side, bilateral split tendon with fleshy belly in a male cadaver, reversed belly of right side palmaris longus in a male cadaver.

The flexor muscles of the forearm develop from the flexor mass, which subsequently divides into 2 layers, superficial and deep.[18] The deep layer gives rise to the flexor digitorum superficialis, flexor digitorum profundus and flexor pollicis longus. The superficial layer of flexor mass gives rise to the pronator teres, flexor carpi radialis, flexor carpi ulnaris and palmaris longus. [19] The embryological basis of duplication of Palmaris longus can be explained due to the additional cleavage of the superficial layer of forearm flexor mass during development, the basis of absence of Palmaris longus can be due to failure of cleavage of the superficial layer of forearm flexor mass during development.[20]
Lalit et al,[21] in their study the morphology and variations of Palmaris Longus and its relation with neighbouring structures were noted. The data thus collected was stored and compared to other studies. Of 62 limbs dissected $55 \quad(88.70 \%)$ showed normal morphology of palmaris longus muscle as per the standard textbook. 5 limbs $(8.06 \%)$ showed complete agenesis. 1 (1.61\%) limb exhibited a fleshy fusiform Palmaris Longus muscle. A Reversed palmaris longus muscle along with accessory Palmaris Longus (1.61\%) was observed in the same limb. Variations of the Palmaris Longus tendon may even confuse an experienced surgeon. Thus, it is important for the reconstructive surgeons or radiologists to be aware of the possibility of variations and its impact on the structures present at the wrist area especially one that might contribute to median or ulnar nerve compression.

\section{CONCLUSIONS}

Palmaris Longus is easily accessible because of it's superficial location. It's length \& breadth is perfectly suitable for repairs. Surgeon must be aware of the variations of palmaris longus muscle. Morphology of Palmaris longus found to be normal, agenesis, fusiform, hybrid, bifurcated tendon and fleshy. Detailed knowledge is helpful for surgeons to use Palmaris Longus for tendon grafting, ligament reconstructions, cosmetic procedures etc. which is helpful for having intricate planning of different surgeries. 
Annals of International Medical and Dental Research

E-ISSN: 2395-2822 | P-ISSN: 2395-2814

Vol-8, Issue-1 | January-February 2022

DOI: 10.53339/aimdr.2022.8.1.23

Page no- 175-179 | Section- Research Article (Anatomy)

\section{REFERENCES}

1. Longhurst G, Stone D, Mahony N. Bilateral reversed palmaris longus muscle: a case report and systematic literature review. Surg Radiol Anat. 2020;42(3):289-295. doi:10.1007/s00276-019-02363-z

2. Iqbal S, Iqbal R, Iqbal F. A Bitendinous Palmaris Longus: Aberrant Insertions and Its Clinical Impact - A Case Report. J Clin Diagn Res. 2015;9(5):AD03AD5. doi:10.7860/JCDR/2015/12182.5954

3. Brones MF, Wilgis EF. Anatomical variations of the palmaris longus, causing carpal tunnel syndrome: case reports. Plast Reconstr Surg. 1978;62(5):798800. doi: 10.1097/00006534-197811000-00037.

4. Troha F, Baibak GJ, Kelleher JC. Frequency of the palmaris longus tendon in North American Caucasians. Ann Plast Surg. 1990;25(6):477-8. doi: 10.1097/00000637-199012000-00008.

5. Thomson NW, Mockford BJ, Cran GW. Absence of the palmaris longus: A population study. Ulster Med J. 2001;70(1):22-24.

6. Morrison JT. A Palmaris Longus Muscle with a Reversed Belly, forming an Accessory Flexor Muscle of the Little Finger. J Anat Physiol. 1916;50(Pt 4):324-6.

7. Fazan VPS. Reversed palmaris longus and median nerve relationship. Case report and literature review. Braz J Morphol Sci. 2007;24(2):88-91.

8. Mathew AJ, Sukumaran TT, Joseph S. Versatile but temperamental: a morphological study of palmaris longus in the cadaver. J Clin Diagn Res. 2015;9(2):AC01-AC3. doi:10.7860/JCDR/2015/11212.5542

9. Jones DP. Bilateral palmaris profundus in association with bifid median nerve as a cause of failed carpal tunnel release. J Hand Surg Am. 2006;31(5):741-3. doi: 10.1016/j.jhsa.2006.02.017.

10. Fatah MF. Palmaris profundus of Frohse and Fränkel in association with carpal tunnel syndrome. J Hand Surg Br. 1984;9(2):142-4.

11. Thompson NW, Mockford BJ, Cran GW. Absence of the palmaris longus muscle: a population study. Ulster Med J. 2001;70(1):22-4.
12. Oluyemi KA, Adesanya OA, Odion BI and Ukwenya VO. Incidence of palmaris longus muscle absence in Nigerian population. Int J Morphol 2008;6(2):305- 8.

13. Ashby BS. Hypertrophy of the palmaris longus muscle; report of a case. J Bone Joint Surg Br. 1964; 46: 230-232.

14. Kumar V, Naveen NS, Murlimanju BV, D'souza PS. A rare muscular variation in the flexor compartment of the forearm. Int J Anat Var (IJAV). 2011; 4: 115- 116.

15. De Smet L. Median and ulnar nerve compression at the wrist caused by anomalous muscles. Acta Orthopaedica Belgica. 2002;68(5):431-6.

16. Mathew AJ, Sukumaran TT, Joseph S. Versatile but temperamental: a morphological study of palmaris longus in the cadaver. J Clin Diagn Res. 2015;9(2):AC01-3. 10.7860/JCDR/2015/11212.5542.

17. Sunitha. R, Prathap Kumar J. A study of palmaris longus muscle: its anatomic variations with embryological significance and clinical importance. Int J Anat Res 2018;6(2.2):5222-5227. https://dx.doi.org/10.16965/ijar.2018.161.

18. Roohi SA, Choon-Sian L, Shalimar A, Tan GH and Naicker AS. A Study on the Absence of Palmaris Longus in a Multi-racial Population. M Ortho J. 2007;1(1):26-28. http://dx.doi.org/10.5704/MOJ.0705.007.

19. Wehbé MA. Tendon graft donor sites. J Hand Surg Am. 1992;17(6):1130-2. doi: 10.1016/s03635023(09)91079-6.

20. Vanderhooft E. The Frequency of and Relationship Between the Palmaris Longus and Plantaris Tendons. Am J Orthop. 1996; 1:38-4

21. Lalit M, Piplani S, Mahajan A, Verma P. Morphological Analysis of Palmaris Longus Muscle and Its Anatomic Variations: A Cadaveric Study In North India. Ital J Anat Embryol. 2019;124(3):443-54.

Source of Support: Nil, Conflict of Interest: None declared 